\title{
Vaginal ligation of descending branch of uterine artery in the management of massive secondary post-partum haemorrhage
}

\author{
Rudrika Chandra ${ }^{1 *}$, Sanjay Singh ${ }^{2}$
}

\begin{abstract}
${ }^{1}$ Department of Obstetrics and Gynecology, 9 Air Force Hospital Halwara, Ludhiana, Punjab, India
${ }^{2}$ Department of Obstetrics and Gynecology, Base Hospital Delhi Cantt, New Delhi, India
\end{abstract}

Received: 14 May 2019

Revised: 29 May 2019

Accepted: 05 June 2019

\author{
*Correspondence: \\ Dr. Smriti Agrawal, \\ E-mail: smritijainagrawal@rediffmail.com
}

Copyright: ( $\odot$ the author(s), publisher and licensee Medip Academy. This is an open-access article distributed under the terms of the Creative Commons Attribution Non-Commercial License, which permits unrestricted non-commercial use, distribution, and reproduction in any medium, provided the original work is properly cited.

\begin{abstract}
A 25 year old lady presented on day 22 of an uneventful caesarean delivery, in a state of class IV haemorrhagic shock, secondary to sudden onset of vaginal bleeding without any inciting cause. Immediate resuscitation was initiated and the cause for massive secondary post-partum haemorrhage ( $\mathrm{PPH}$ ) was identified as an actively bleeding vessel at 3 ' $\mathrm{O}$ ' clock position on a visibly healthy cervix with a well contracted uterus. This was the descending branch of left uterine artery, which was ligated after pulling the cervix with a sponge holder towards the introitus and application of Vicryl No 1-0 suture. The bleeding decreased significantly post vascular ligation. Further exploration of vagina and cervix did not reveal any active bleeding or laceration and no retained placental tissue was found inside uterine cavity on ultrasound examination. This is a rare case of Massive Secondary PPH in a post-caesarean patient due to spontaneous giving way of descending branch of uterine artery.
\end{abstract}

Keywords: Descending branch of uterine artery, Fertility preserving surgical approach, Hemorrhagic shock, Secondary post-partum haemorrhage (PPH), Vaginal ligation

\section{INTRODUCTION}

Secondary postpartum haemorrhage (PPH) is defined as excessive vaginal bleeding from $24 \mathrm{~h}$ after delivery up to 6 weeks postpartum. Common causes include retained products of conception, subinvolution of the placental bed, and endometritis. ${ }^{1}$ Rare causes include pseudoaneurysm of the uterine artery, arteriovenous malformations, caesarean scar dehiscence and choriocarcinoma.

Herein, authors report a case of Secondary PPH due to spontaneous rupture of descending branch of uterine artery leading to massive vaginal bleeding managed by a fertility preserving surgical approach. To our knowledge, this is the first reported case of "spontaneous giving way of descending branch of uterine artery as the cause of secondary postpartum haemorrhage" which was treated by surgical procedure..

\section{CASE REPORT}

A 25-year-old Primigravida presented at 38 completed weeks of gestation with labour pains and underwent augmentation of labour with intravenous (IV) oxytocin infusion and artificial rupture of membranes. She was taken for an emergency caesarean section due to late onset foetal decelerations on cardiotocography. She delivered a healthy female baby of $3.0 \mathrm{~kg}$ weight with no significant intraoperative findings. Postoperative period 
was uneventful and the patient was discharged on Day 3 of caesarean delivery.

She was brought to the emergency room (ER) on Day 22 of caesarean delivery in a state of shock with a history of sudden onset of painless bright red vaginal bleeding since $1 \mathrm{hr}$. There was no $\mathrm{H} / \mathrm{O}$ any fever, foul smelling lochia, antecedent trauma or intercourse. This apparently causeless secondary PPH had led to loss of around 2 litres of blood at home prior to reaching the hospital. On arrival, the patient was unresponsive with cold and clammy extremities. Her carotid pulse rate was 140 beats per minute, peripheral pulses feeble, blood pressure not recordable and $\mathrm{SpO}_{2} 82 \%$ on room air.

Immediate resuscitation was started after securing two large bore IV access lines and drawing blood sample for testing and cross matching. $3500 \mathrm{ml}$ of Ringer lactate was rapidly infused following which the patient's vitals showed signs of slight improvement. After initial resuscitation, an attempt was made to identify the cause of bleeding per vaginum. Per abdominally, the uterus was not palpable and there were no signs of subinvolution. An arterial bleeding was identified on cervix at 3 o'clock position, possibly the descending branch of left uterine artery. The lips of cervix were grasped with sponge holding forceps and cervix pulled down towards introitus followed by ligation of descending branch of left uterine artery at 3 ' $\mathrm{O}$ ' clock position with Vicryl 1-0 suture applied just below the cervicovaginal junction. Once the active source of bleeding was sutured, vaginal exploration could be performed and there was no evidence of any genital tract laceration. Ultrasound examination ruled out any retained placental tissue inside uterine cavity and there was no evidence of intrabdominal collection.

The patient was catheterised and 2 units of crossmatched whole blood were transfused following the cessation of active bleeding. Her pre-transfusion $\mathrm{Hb}$ was $3.8 \mathrm{gm} \%$. She was started on prophylactic parenteral antibiotics. Patient's vitals gradually improved and she became responsive. After 24 hrs of transfusion, she was given 2 units of crossmatched packed red cells and her post transfusion $\mathrm{Hb}$ was $7 \mathrm{gm} \%$. There was no active vaginal bleeding following the ligation of descending branch of uterine artery.

After 5 days, she was discharged on oral haematinics and reviewed after 2 weeks without any significant complaints. This case brings forth the rare possibility of bleeding from descending branch of uterine artery as a cause of secondary PPH which may prove to be life threatening if not recognized and managed with timely intervention.

\section{DISCUSSION}

Secondary postpartum haemorrhage ( $\mathrm{PPH})$ is defined as excessive vaginal bleeding from 24 hour after delivery up to 6 weeks postpartum. ${ }^{2}$ Unlike the definition of primary $\mathrm{PPH}$, there is no clear or standard definition for quantity of the blood loss associated with secondary PPH, and clinical expressions of this definition vary from 'increased lochia' to massive bleeding. The diagnosis is therefore all too often subjective, which may account for the numerous variations in reported incidence. Overall, the reported incidence of secondary PPH in the developed world varies from $0.47 \%$ to $1.44 \%$. $^{3,4}$

The aetiology of secondary PPH is diverse, and management is dependent on identifying the cause and tailoring treatment appropriately. In contrast to primary $\mathrm{PPH}$, the published work on the management of secondary PPH is limited. ${ }^{5}$ The majority of cases are associated with minor morbidities but may still require re-admission to hospital, use of antibiotics and surgical intervention. In more extreme cases, major morbidity may require hysterectomy, arterial ligation or radiological intervention. ${ }^{6}$ Despite the use of all available interventions, maternal death may still result from massive secondary PPH.

The major cause of secondary PPH is subinvolution of the uterus due to retained placental tissue and/or endometritis. Lower genital tract lacerations/hematoma may present as delayed PPH following traumatic or instrumental vaginal delivery. Other uncommon causes could be dehiscence of caesarean section scar, arteriovenous malformation or uterine artery pseudoaneurysm. Possibility of gestational trophoblastic neoplasia should be kept in mind in a case of prolonged irregular bleeding per vaginum post-delivery.

The review of literature did not show any reported case of secondary PPH due to spontaneous rupture of descending branch of uterine artery. However, ligation of a bleeding aberrant cervical artery has been reported following vacuum suction termination of early pregnancy. ${ }^{7}$ Ligation of descending branch of uterine arteries vaginally has been advocated by Ross to control PPH not responding to conventional conservative methods. ${ }^{8}$ This procedure can prevent an unnecessary hysterectomy with its consequent physical and mental trauma. There is the added advantage of shorter stay in the hospital. In our case too, we controlled the genital bleeding by ligating descending branches of uterine artery vaginally. Ligation of descending branch of uterine artery has been advocated as an initial approach before proceeding to internal iliac artery ligation or abdominal hysterectomy in cases of intractable genital tract bleeding. ${ }^{9}$

\section{CONCLUSION}

There are case reports of successful ligation of descending branch of uterine artery to control intractable genital tract bleeding as a fertility sparing initial approach in cases of vacuum suction termination, cervical pregnancy management and primary $\mathrm{PPH}$ following caesarean delivery for placenta previa. But none to our 
knowledge, demonstrating secondary PPH due to spontaneous giving way of descending branch of uterine artery which was in this case managed successfully by ligating the descending branch of left uterine artery hence preserving her uterus and terminating her life-threatening vaginal bleeding. Thus, it is prudent to keep this entity in mind in cases of secondary PPH.

Funding: No funding sources

Conflict of interest: None declared

Ethical approval: Not required

\section{REFERENCES}

1. Khong TY, Khong TK. Delayed postpartum hemorrhage: a morphologic study of causes and their relation to other pregnancy disorders. Obstet Gynecol. 1993;82(1):17-22.

2. Thompson W, Harper M. Postpartum haemorrhage and abnormalities of the third stage of labour. In: Chamberlain G, Steer P, eds. Turnbull's Obstetrics, $3^{\text {rd }}$ Ed. Edinburgh: Churchill Livingstone. 2001:61933.

3. Hoveyda F, MacKenzie IZ. Secondary postpartum haemorrhage: incidence, morbidity and current management. BJOG. 2001;108(9):927-30.

4. King PA, Duthie SJ, Dong ZG, Ma HK. Secondary postpartum haemorrhage. Aust N Z J Obstet Gynaecol. 1989;29(4):394-8.
5. Alexander J, Thomas PW, Sanghera J. Treatments for secondary postpartum haemorrhage (Review). Cochrane Database Syst Rev. 2008;(1): CD002867.

6. Ledee N, Ville Y, Musset D, Mercier F, Frydman R, Fernandez H. Management in intractable obstetric haemorrhage: an audit study on 61 cases. Eur J Obstet Gynecol Reprod Biol.2001;94(2):189-96.

7. Chordia SK. Management of a bleeding aberrant cervical artery following vacuum suction termination. Case report. $\mathrm{Br} \quad \mathrm{J}$ Obstet Gynaecol.1988;95(4):411-3.

8. Ross I. Ligation of uterine arteries per vagina in a case of recurrent secondary postpartum hemorrhage following cesarean. Aust NZJ Obstet Gynecol. 1963;5:251-8.

9. Moirangthem RS, Ngangom IS, Naorem NS, Chanam MS, Ariban LD . Bilateral vaginal ligation of descending branch of the uterine artery in the management of heavy genital tract bleeding. Case report. J Obstet Gynecol India. 2005;55(6):555-6.

Cite this article as: Chandra $\mathrm{R}$, Singh $\mathrm{S}$. Vaginal ligation of descending branch of uterine artery in the management of massive secondary post-partum haemorrhage. Int J Reprod Contracept Obstet Gynecol 2019;8:2937-9. 